\title{
A light upon the horizon: young analytical chemists forging new scientific pathways during an economic downturn
}

\author{
Marc R. Knecht • Sylvia Daunert
}

Published online: 15 March 2009

(C) Springer-Verlag 2009

The first decade of the twenty-first century has brought us social, environmental, and economic turmoil. We cannot ignore the wars and genocides taking place in different parts of the world, from Iraq to Afghanistan to Rwanda. Terrorism has transgressed from being a potential nightmare to a sad reality spanning the globe. The environmental insults bestowed upon the Earth by industrial growth are starting to take a toll on the welfare of the planet. All of these issues are compounded by the recent worldwide economic collapse. As human beings and scientists, all of the above problems are of concern, and pose a challenge in terms of how to move science forward without losing the momentum gained during the wealth experienced in the last ten years of the twentieth century. Two of the most serious issues currently facing the world's scientific community are climate change and the looming exhaustion of traditional fossil fuels. Both of these arenas offer vast research opportunities for analytical chemists, either through detection and quantitation methods or through the creation, characterization and optimization of advanced and efficient energy sources. While the possibilities for scientific research advancement in these fields are limitless, the current global economic downturn paints a new picture of the reality of addressing these major goals. In such troubled times, research funding opportunities direct scientists to focus on the bigger picture of the day, rather than on highly specialized research problems. There is no question that, in

M. R. Knecht $\cdot$ S. Daunert $(\bowtie)$

Department of Chemistry, University of Kentucky,

Lexington, KY 40506-0055, USA

e-mail: daunert@uky.edu recent years, scientific funding has been tighter in the United States as well as in Europe, Japan, and most other countries that traditionally support research; however, this should not prevent the youngest generation of scientists from succeeding and making their mark in their selected discipline, just as previous generations have in similar times. Even after the crash of Wall Street in 1929 and during the Great Depression, science was able to advance and produce new concepts that are today considered basic chemical principles, such as electronegativity, which was introduced by Linus Pauling in 1932. Other important scientific milestones of those times include the discovery of Pluto in 1930, the invention of the electronic microscope, the synthesis of artificial rubber and neoprene, as well as the invention of the electronic television in 1933. The first clinical use of penicillin dates back to 1931, and in 1937 insulin was employed to control diabetes. In the late 1930 s there was a boom in synthetic chemistry, and those years produced polymers such as Teflon, Nylon, polyethylene glycol, and a long list of drugs and vitamins that still constitute a pillar for modern drug discovery and treatment [1].

The economic collapse of 2008 and 2009 represents the second longest recession in the United States since the Second World War [2]. The recession has now become a worldwide issue, affecting countries from Europe to South America to Asia. It is without question that all must tighten their belts during such times and spend money in the most responsible manner. To that end, governments are required to spend federal resources in ways that will restart a stuttering economy and bring about more prosperous economic times. Presently, the United States Congress has passed a large stimulus package of $\$ 787$ billion that promotes a mix of infrastructure development, employment incentive plans and strategic tax cuts, all aimed at economic development [3]. While we will not know the outcome of 
such plans before their implementation, it is critical that funds directed towards scientific research play a role in any such stimulus. Under the current bill, approx. $\$ 16.5$ billion will be allocated to scientific research, with $\$ 3$ billion for the NSF and $\$ 8.5$ billion for the NIH. A significant portion of the stimulus funds will be directed towards energy research via agencies such as the Department of Energy, representing a strong emphasis on burgeoning fields [4]. Basic science, especially that in applied analytical chemistry, stimulates the generation of new products and methods, which can address global concerns while resulting in job creation when this science is adapted at the industrial level. Stimulus scientific funding must undoubtedly be directed at large-scale issues, which permits rising analytical chemists - the focus of the present journal issue - to apply their scientific expertise to meet these global-scale concerns.

The deteriorating condition of the environment and the consumption of fossil fuels represent deep research areas that will likely require many years to decades of hard scientific studies to solve the problems involved. Global warming represents a threat to the Earth's environment due to the production of $\mathrm{CO}_{2}$ gas as a byproduct of fossil fuel combustion. As studied by the Intergovernmental Panel on Climate Change in 2005, in the last 100 years, the surface temperature of the Earth has risen by approximately $0.74{ }^{\circ} \mathrm{C}$, with further increases projected for the twenty-first century [5]. While such changes seem unimpressive on the small scale, their lasting effects, which include glacier retreat, a rise in sea level and changes to global weather patterns, can result in the rapid spread of disease and extended famines. In light of these facts, new research avenues are required to develop environmentally friendly schemes that can be employed in detection methods to monitor the deterioration of the ecosystem in a more rapid, high-throughput manner. In addition, sensitive new biosensors are required for biomedical applications as new diseases or more virulent strains arise in the hardest hit areas. New materials, detection systems, and devices made of natural resources will become key players in the repertoire of environmentally friendly tools. In that regard, it is a fantastic opportunity for scientists in the field of bionanotechnology to understand and adapt natural processes such as biomineralization, molecular recognition and actuation, as well as energy storage and production, in the creation of new technologies. Despite the impressive research in bionanotechnology already being conducted in many laboratories, the field is still in its infancy. Thus, new investigators must be challenged to find innovative avenues of research that can contribute to fully addressing these issues.

In addition to global warming, changes to the planetary energy grid are required. These changes are needed in response to the well-known threat of the final consumption of fossil fuels. Current estimated rates of consumption suggest that nearly all crude oil sources will be exhausted within 40 years [6]. While such fuels will be available in the short term, new methods of energy production are required. These challenges can be addressed at the chemical level, with a multidisciplinary team focused on the development of new energy-based materials. Indeed, Honda has already begun production of the FCX Clarity model car, which uses hydrogen fuel cell technologies as its mode of action. In a variant of this machinery, Sony has developed biofuel cells with the ability to power electrical devices from the breakdown of glucose. These energy sources rely on miniaturized efficient electrochemical cells based on the use of glucose as the substrate of an enzyme working in tandem with another one to generate electrons, followed by the conduction of these electrons within an electrochemical cell. The result is a glucose-powered rechargeable battery. Such technologies are sought after as replacements for present-day energy sources, as they rely on renewable resources rather than exhaustible fossil fuels. In addition, these technologies also do not produce deleterious byproducts that can contribute towards environmental deterioration. The call to the electrochemical community is becoming louder, with resilient cries for new energetic systems. The main issue with immediate turnover is that the present-day infrastructure is not particularly amenable to the $\mathrm{H}_{2}$ economy; however, once fossil fuels are consumed, complete turnover to secondary systems will be required. Studies on making this possible go beyond the scientific to change the means by which automobile refueling is performed, which should be handled with a degree of urgency.

In light of the current global situation at the confluence of an economic downturn with global environmental/energy issues, science has become extensively challenged. Einstein once said: "We can't solve problems by using the same kind of thinking we used when we created them." Einstein was right, and this is why renewed blood and creativity is needed to tackle existing problems. It lies upon the next generation of scientists to implement new thinking processes and lead the way in addressing these significant issues. While research advances in proteomics, genomics, lipidomics, bio/chemical detection, the generation of new quantitation methodologies, and advances in separation science are already being met by the newest members of the scientific community, all of these advances have been formed with the knowledge gained from the great scientific expansion of the twentieth century. Similar new strides can be achieved in response to modern threats, as different threats of the past were the root cause of previous scientific growth. Optimism needs to persist. As mentioned above, even in times of severe economic hardship and depression, valuable science has emerged. Depressions and economic 
downturns come and go in cycles, but the advances realized by the scientific community are always positive and create new stepping stones for future discoveries. In the current issue of Analytical and Bioanalytical Chemistry, we focus on the research of the youngest members of the analytical community as their independent careers begin to shine forth. Their research is as broad as it is deep, focusing on biomedical to materials applications, with many variations in-between. We encourage you, the reader, to enjoy the research strides that are presented herein, and suggest discussions with our authors concerning their research. Major scientific advances are made through open communication, discussions, and collaborations. To the authors: we thank you for your contributions and look forward to your continued success.

\section{References}

1. Magic Dragon Multimedia (2004) SF timeline 1930-1940 (online). http://www.magicdragon.com/UltimateSF/timeline1940.html

2. Kaiser E (2009) Economists see longest recession since World War Two. Reuters News Service 10 Jan 2009 (http://www.reuters.com/ article/pressReleasesMolt/idUSTRE5090QL20090110)

3. Fritze J (2009) Congress passes \$787B economic stimulus bill. USA Today 15 Feb 2009 (http://www.usatoday.com/news/washington/ 2009-02-13-stimulus-bill_N.htm)

4. Finin T (2009) NSF and science increments survive stimulus conference (on UMBC eBiquity Research Group website). http:// ebiquity.umbc.edu/blogger/2009/02/12/nsf-and-science-incrementssurvive-stimulus-conference/

5. IPCC (2009) Intergovernmental Panel on Climate Change website. http://www.ipcc.ch/

6. US DOE (2007) Basic research needs: catalysis for energy. United States Department of Energy, Washington DC 